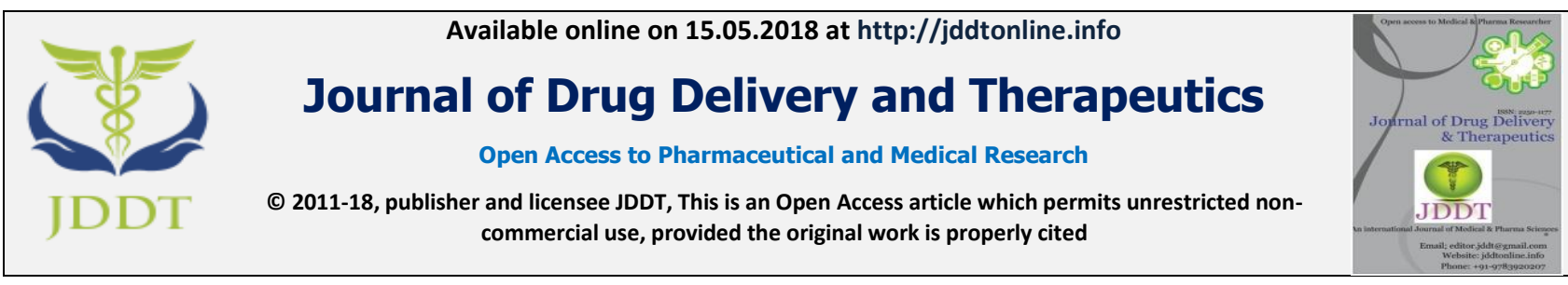

Open $\odot$ Access

Review Article

\title{
A REVIEW ON FORMULATION APPROACHES IN IMMEDIATE RELEASE TABLET
}

\author{
Rajveer Bhaskar, Monika Ola, Sandip S. Bhamare* \\ Dept. of Quality Assurance, R.C. Patel College of Pharmaceutical Education \& Research, Shirpur, Dhule (M.S.) India
}

\begin{abstract}
Sometimes immediate onset of action is required than conventional treatment in many patients. Among all dosage forms tablet is the most popular dosage form existing today because of its convenience of self-administration, compactness and easy manufacturing. to overcome these drawbacks, immediate release dosage form has emerged as alternative oral dosage forms. Immediate drug release dosage forms disintegrate quickly after administration with enhanced rate of dissolution. The basic approach used in development tablets is the use of superdisintegrants like Cross linked Polyvinylpyrrolidone or crospovidone (Polyplasdone), Sodium starch glycolate (Primogel, Explotab), carboxymethylcellulose (Croscarmellose) etc. In this field immediate release liquid dosage forms and parenteral dosage form have also been introduced for treating patients. The development of immediate release therapy also provides an opportunity for a line extension in the marketplace, a wide range of drugs e.g., anticoagulant and other drugs can be considered candidates for this dosage form. The development of immediate release therapy also provides an opportunity for a line extension in the marketplace, a wide range of drugs e.g., anticoagulant and other drugs can be considered candidates for this dosage form.
\end{abstract}

Keywords: Immediate release, super disintegrates, direct compression, wet Granulation

Article Info: Received 17 March, 2018; Review Completed 24 April 2018; Accepted 26 April 2018; Available online 15 May 2018

Cite this article as:

Bhaskar R, Ola M, Bhamare SS, A review on formulation approaches in immediate release tablet, Journal of Drug Delivery and Therapeutics. 2018; 8(3):153-161 DOI: http://dx.doi.org/10.22270/jddt.v8i3.1748

${ }^{*}$ Address for Correspondence:

Sandip Subhash Bhamare, Dept. of Quality Assurance, R.C. Patel College of Pharmaceutical Education \& Research, Shirpur, Dhule (M.S.) India

\section{INTRODUCTION}

In that present study and research novel drug delivery systems are developed for expanding indications, extending product life cycles and generating opportunities. Oral administration is the most popular route for systemic effects due to its ease of ingestion, pain, avoidance, versatility and most importantly patient compliance. The development of enhanced oral protein delivery technology by immediate release tablets which may release the drugs at an enhanced rate are very promising for the delivery of poorly soluble drugs high molecular weight protein and peptide. ${ }^{1,2}$ The oral route remains the perfect route for the administration of therapeutic agents because the low cost of therapy, manufacturing and ease of administration lead to high levels of patient compliance. Many patients require quick onset of action in particular therapeutic condition and consequently immediate release of medicament is required. It is estimated that $50 \%$ of the population is affected by this problem, which results in a high incidence of ineffective therapy.

Immediate release tablets are those which disintegrate rapidly and get dissolved to release the medicaments. Immediate release may be provided for by way of an appropriate pharmaceutically acceptable diluent or carrier, which diluent or carrier does not prolong, to an appreciable extent, the rate of drug release and/or absorption. ${ }^{2,3}$ This term excludes formulations which are adapted to provide for "modified", "controlled", "sustained", "prolonged", "extended" or "delayed" release of drug. Release term includes the provision (or presentation) of drug from the formulation to the gastrointestinal tract, to body tissues and/or into systemic circulation. 
Anatomy and physiology of stomach

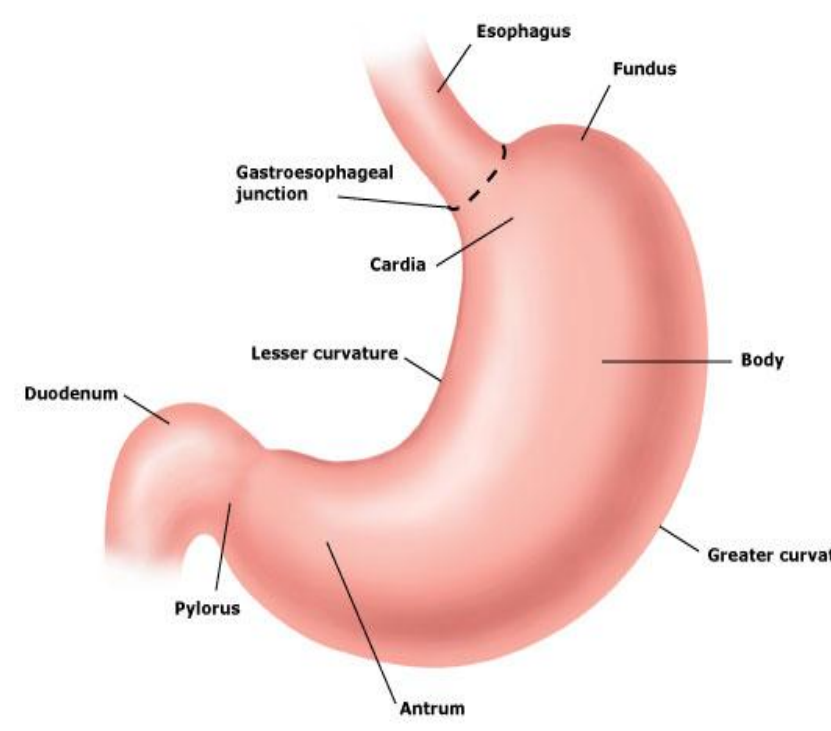

Figure 1: Anatomy of stomach

The stomach is part of the digestive system and is connected to the:

- Esophagus - a tube-like organ that connects the mouth and throat to the stomach. The area where the esophagus joins the stomach is called the gastroesophageal (GE) junction.

- Small intestine (small bowel) - a long tube-like organ that extends from the stomach to the colon (large intestine or large bowel). The first part of the small intestine is called the duodenum, and it is this part that is connected to the stomach.

- The stomach is divided into 5 regions: The cardia is the first part of the stomach below the esophagus. It contains the cardiac sphincter, which is a thin ring of muscle that helps to prevent stomach contents from going back up into the esophagus.

- The fundus is the rounded area that lies to the left of the cardia and below the diaphragm.

- The body is the largest and main part of the stomach. This is where food is mixed and starts to break down ${ }^{3,1}$.

- The antrum is the lower part of the stomach. The antrum holds the broken-down food until it is ready to be released into the small intestine. It is sometimes called the pyloric antrum.

- The pylorus is the part of the stomach that connects to the small intestine. This region includes the pyloric sphincter, which is a thick ring of muscle that acts as a valve to control the emptying of stomach contents (chyme) into the duodenum (first part of the small intestine). The pyloric sphincter also prevents the contents of the duodenum from going back into the stomach. ${ }^{2}$
It is the study of absorption, distribution, metabolism and excretion. After absorption, drug attains therapeutic level and therefore elicits pharmacological effect, so both rate and extend of absorption is important. In conventional dosage form there is delay in disintegration and therefore dissolution is fast. Drug distribution depends on many factors like tissue permeability, perfusion rate, binding of drug to tissue, disease state, drug interaction etc. Duration and intensity of action depends upon rate of drug removal from the body or site of action i.e. biotransformation. Decrease in liver volume, regional blood flow to liver reduces the biotransformation of drug through oxidation, reduction and hydrolysis. Excretion by renal clearance is slowed, thus half-life of renal excreted drugs increase. ${ }^{3,4}$

\section{Pharmacodynamics}

Drug reception interaction impaired in elderly as well as in young adult due to undue development of organ. Decreased ability of the body to respond reflexive stimuli, cardiac output, and orthostatic hypotension may see in taking antihypertensive like prazosin. Decreased sensitivity of the CVS to $\alpha$-adrenergic agonist and antagonist. Immunity is less and taken into consideration while administered antibiotics. ${ }^{1,4}$
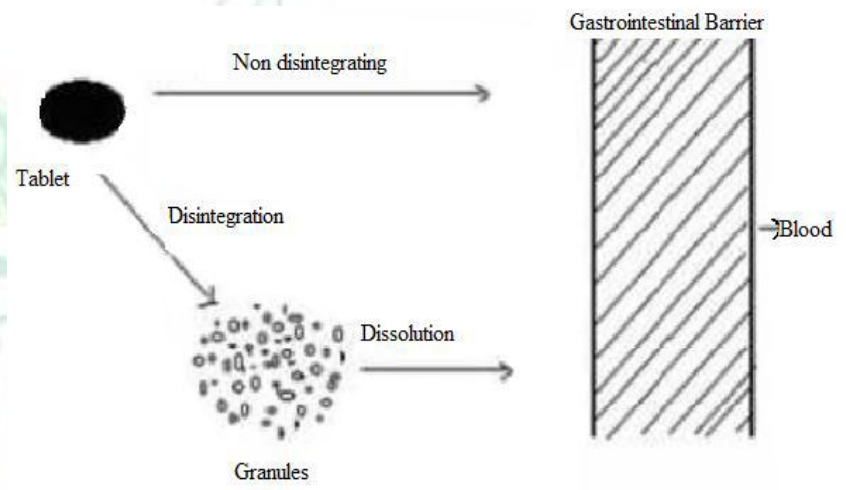

Figure 2: Absorption of Drug from the GIT. ${ }^{3}$

Altered response to drug therapy-elderly show diminished bronchodilator effect of theophylline shows increased sensitivity to barbiturates.

Concomitant illnesses are often present in elderly, which is also taken into consideration, while multiple drug therapy prescribed.

Research workers have clinically evaluated drug combination for various classes' cardiovascular agents, diuretics, anti-hypertensive etc. for immediate release dosage forms. The combination choice depends on disease state of the patient.

\section{Desired Criteria for Immediate Release Drug Delivery System:}

Immediate release dosage form should- ${ }^{2}$

- It should not leave minimal or no residue in the mouth after oral administration.

- Exhibit low sensitivity to environmental condition as humidity and temperature. 
- $\quad$ Be manufactured using conventional processing and packaging equipment at low cost.

- Rapid dissolution and absorption of drug, which may produce rapid onset of action

- In the case of solid dosage it should dissolve or disintegrate in the stomach within a short period.

- In the case of liquid dosage form it should be compatible with taste masking.

- Be portable without fragility concern.

- Have a pleasing mouth feel.

Merits of Immediate Release Drug Delivery System:

Adaptable and amenable to existing processing and packaging machinery ${ }^{5}$

- Cost- effective

- Improved solubility of the pharmaceutical composition; Decreased disintegration and dissolution times for immediate release oral dosage forms.

- Improved compliance/added convenience

- Improved stability, bioavailability

- Suitable for controlled/sustained release actives
- $\quad$ Allows high drug loading.

- Ability to provide advantages of liquid medication in the form of solid preparation. ${ }^{6}$

\section{GENERAL EXCIPIENTS USED IN IMMEDIATE RELEASE TABLETS}

\section{Ideal characteristics of excipients ${ }^{6}$}

- They must be free of any unacceptable microbiological load.

- They must be color compatible, should not change shade of color in the formulation.

- If product is classified as food, the diluents and other excipients must be approved food additives.

- They must not have an adverse effect on the bioavailability of the products. They must be nontoxic with no pharmacological activity and acceptable to the regulatory agencies in the countries where the product is to be marketed.

- They must be commercially available in an acceptable grade in countries where the product is to be manufacture.

- $\quad$ Cost effective.

- $\quad$ They must be physiologically inert.

- They must be physically and chemically stable by themselves and in combination with other drugs and tablet components. ${ }^{6}$

Table 1: Lists of different excipients used in the design of tablets

\begin{tabular}{|l|l|l|}
\hline Excipients & Functions & Examples \\
\hline Diluents & $\begin{array}{l}\text { Used as filler designed make up the required } \\
\text { bulk of the tablet. }\end{array}$ & $\begin{array}{l}\text { Lactose, starch, mannitol, } \\
\text { sucrose, sorbitol etc. }\end{array}$ \\
\hline $\begin{array}{l}\text { Binders and } \\
\text { Adhesives }\end{array}$ & $\begin{array}{l}\text { These are used to produce cohesive compact, } \\
\text { either in dry or wet form. }\end{array}$ & $\begin{array}{l}\text { Hydroxy propyl methyl cellulose, acacia, } \\
\text { starch, cellulose derivative etc. }\end{array}$ \\
\hline Disintegrants & Used to facilitate a breakup of the tablet. & Starch, clays, cellulose, alginate, povidone etc \\
\hline Lubricants & $\begin{array}{l}\text { Used to reduce the friction during tablet } \\
\text { ejection between the walls of die cavity. }\end{array}$ & $\begin{array}{l}\text { Stearic acid, stearic acid salts, polyethylene } \\
\text { glycol, talc, waxes etc. }\end{array}$ \\
\hline Antiadherants & $\begin{array}{l}\text { Used to reduce sticking or adhesion of any } \\
\text { tablet granules or powder to the faces of } \\
\text { punches or die wall. }\end{array}$ & $\begin{array}{l}\text { Talc, polyethylene glycol, hydrogenated } \\
\text { castor oil, glyceryl behenate etc. }\end{array}$ \\
\hline $\begin{array}{l}\text { Glidants or flow } \\
\text { promoters }\end{array}$ & $\begin{array}{l}\text { Used to promote flow of the tablet granules or } \\
\text { powder material by reducing friction within } \\
\text { particles. }\end{array}$ & Silica derivatives, talc, corn starch etc. \\
\hline $\begin{array}{l}\text { Colors, flavors and } \\
\text { sweeteners }\end{array}$ & $\begin{array}{l}\text { Used to enhance the Organoleptic properties } \\
\text { and acceptability of the product. }\end{array}$ & $\begin{array}{l}\text { FD \& C, D\&C dyes and lakes, banana, bubble } \\
\text { gum, strawberry, vanilla flavors, aspartame, } \\
\text { neotame, saccharin, mannitol etc. }\end{array}$ \\
\hline
\end{tabular}

\section{A. Disintegrants:}

As disintegrants sodium starch glycolate, sodium carboxymethyl cellulose, calcium carboxymethyl cellulose, croscarmellose sodium, Crospovidone, polyvinyl polypyrrolidone, methyl cellulose, microcrystalline cellulose, powdered cellulose, lower alkyl-substituted hydroxypropyl cellulose, polacrilin potassium, starch, pregelatinized starch, sodium alginate, and mixtures thereof. The amount of disintegrant included in the dosage form will depend on several factors, including the properties of the dispersion, the properties of the porosigen and the properties of the disintegrants selected. Generally, the disintegrant will comprise from $1 \% \mathrm{w} / \mathrm{w}$ to $25 \% \mathrm{w} / \mathrm{w}$ of the dosage form.

\section{Mechanism of tablet Disintegration}

The tablet breaks to primary particles by one or more of the mechanisms listed below: ${ }^{4}$

1) By capillary action

2) By swelling

3) Because of heat of wetting

4) Due to disintegrating particle/particle repulsive force

5) Due to deformation

6) Due to release of gases

7) By enzymatic action 
Table 2: Classification of superdisintegrants

\begin{tabular}{|c|l|l|l|}
\hline Sr no. & Structure type & Description & Trade name \\
\hline 1. & $\begin{array}{l}\text { Modified starches } \\
\text { (Sodium starch glycolate) }\end{array}$ & $\begin{array}{l}\text { Sodium carboxy methyl starch, the carboxymethyl groups } \\
\text { induced hydrophilicity and cross-linking reduces solubility. }\end{array}$ & $\begin{array}{l}\text { Explotab } \\
\text { Primojel }\end{array}$ \\
\hline 2. & $\begin{array}{l}\text { Modified cellulose } \\
\text { (Crosscarmallose NF) }\end{array}$ & $\begin{array}{l}\text { Sodium carboxy methyl cellulose which has been cross-linked } \\
\text { to render the material insoluble. }\end{array}$ & $\begin{array}{l}\text { Ac-Di-Sol } \\
\text { Nymcel } \\
\text { Solutab }\end{array}$ \\
\hline 3. & $\begin{array}{l}\text { Cross-linked } \\
\text { polyvinylpyrrolidone } \\
\text { (Crosspovidone) }\end{array}$ & $\begin{array}{l}\text { Cross-linked polyvinylpyrrolidone, the high molecular weight } \\
\text { and cross-linking render the material insoluble in water. }\end{array}$ & $\begin{array}{l}\text { Crospovidone } \\
\text { Kollidon } \\
\text { Polyplasdone }\end{array}$ \\
\hline
\end{tabular}

\section{B. Binder}

Binder is a material used to bind other materials together. Microcrystalline cellulose (MCC) is commonly used as a filler-binder in direct compression because of its good bonding properties. Other commonly used binders in direct compression include starches and their derivatives, such as pregelatinised and granulated starches.

\section{Surfactants}

One very useful class of excipients is surfactants, preferably present from 0 to $10 \%$ w/w. Suitable surfactants include fatty acid and alkyl sulfonates; commercial surfactants such as benzalkonium chloride, dioctyl sodium sulfosuccinate, polyoxyethylene sorbitan fatty acid esters, natural surfactants such as sodium taurocholic acid, lecithin, and other phospholipids and mono and diglycerides; and mixtures thereof. Such materials can advantageously be employed to increase the rate of dissolution by, for example, facilitating wetting, or otherwise increase the rate of drug release from the dosage form. ${ }^{9}$

\section{D. pH Modifiers}

Inclusion of $\mathrm{pH}$ modifiers such as acids, bases, or buffers may also be beneficial in an amount of from 0 to $10 \%$ w/w. Acidic pH modifiers (e.g., acids such as citric acid or succinic acid) retard the dissolution of the pharmaceutical composition when the dispersion polymer is anionic. Alternatively, basic $\mathrm{pH}$ modifiers (e.g., sodium acetate or amines) enhance the rate of dissolution of the same types of pharmaceutical composition. $^{8}$

\section{E. Diluents}

Examples of other matrix materials, fillers, or diluents include lactose, mannitol, xylitol, dextrose, sucrose, sorbitol, compressible sugar, microcrystalline cellulose (MCC), powdered cellulose, starch, pregelatinized starch, dextrates, dextran, dextrin, dextrose, maltodextrin, calcium carbonate, dibasic calcium phosphate, tribasic calcium phosphate, calcium sulfate, magnesium carbonate, magnesium oxide, poloxamers, polyethylene oxide, hydroxypropyl methyl cellulose (HPMC) and mixtures thereof. ${ }^{9}$

\section{F. Lubricants}

Examples of lubricants include calcium stearate, glyceryl monostearate, glyceryl palmitostearate, hydrogenated vegetable oil, light mineral oil, magnesium stearate, mineral oil, polyethylene glycol, sodium benzoate, sodium lauryl sulfate, sodium stearyl fumarate, stearic acid, talc and zinc stearate. ${ }^{10}$

\section{G. Glidants}

Examples of glidants include silicon dioxide, talc and cornstarch. A glidant is a substance that is added to a powder to improve its flowability. A glidant will only work at a certain range of concentrations. Above a certain concentration, the glidant will in fact function to inhibit flowability (which means that there's a critical concentration to be used if increasing powder's flowability is intended with respect to the glidant and the powder properties). In tablet manufacture, glidants are usually added just prior to compression. ${ }^{10}$

\section{TECHNIQUE USED FOR THE PREPARATION OF IMMEDIATE RELEASE TABLETS}

Several Technologies are available to manufacture immediate release tablets. The most common preparation methods are moulding, lyophilisation or freeze drying, direct compression, spray drying and sublimation.

\section{* Tablet molding technique \\ * Direct compression technique \\ * Granulation technique \\ * Direct compression method}

In this method, tablets are compressed directly from the mixture of the drug and excipients without any preliminary treatment. The mixture to be compressed must have adequate flow properties and cohere under pressure thus making pretreatment as wet granulation unnecessary. Few drugs can be directly compressed into tablets of acceptable quality. A type of disintegrant and its proportion are of prime importance. The other factors to be considered are particle size distribution, contact angle, pore size distribution, tablet hardness and water absorption capacity. All these factors determine the disintegration. The disintegrant addition technology is cost effective and easy to implement at industrial level.

\section{* Dry granulation}

In dry granulation process the powder mixture is compressed without the use of heat and solvent. The two basic procedures are to form a compact of material by compression and then to mill the compact to obtain granules. Two methods are used for dry granulation. ${ }^{14,12}$

\section{a. Slugging process}


Granulation by slugging is the process of compressing dry powder of tablet formulation with tablet press having die cavity large enough in diameter to fill quickly. The accuracy or condition of slug is not too important. Only sufficient pressure to compact the powder into uniform slugs should be used. Once slugs are produced they are reduced to appropriate granule size for final compression by screening and milling. ${ }^{11,13}$

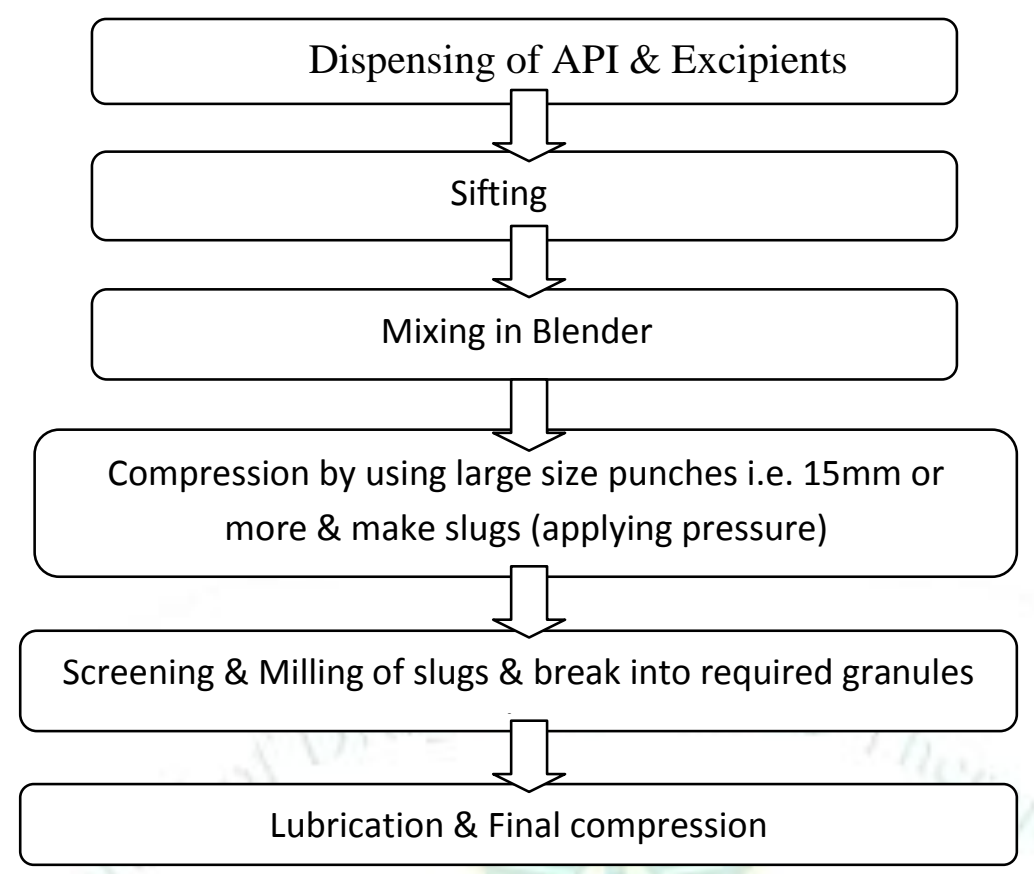

\section{b. Roller compaction}

The compaction of powder by means of pressure roll can also be accomplished by a machine called chilsonator. Unlike tablet machine, the chilsonator turns out a compacted mass in a steady continuous flow. The powder is fed down between the rollers from the hopper which contains a spiral auger to feed the powder into the compaction zone. Like slugs, the aggregates are screened or milled for production into granules ${ }^{15,12}$.

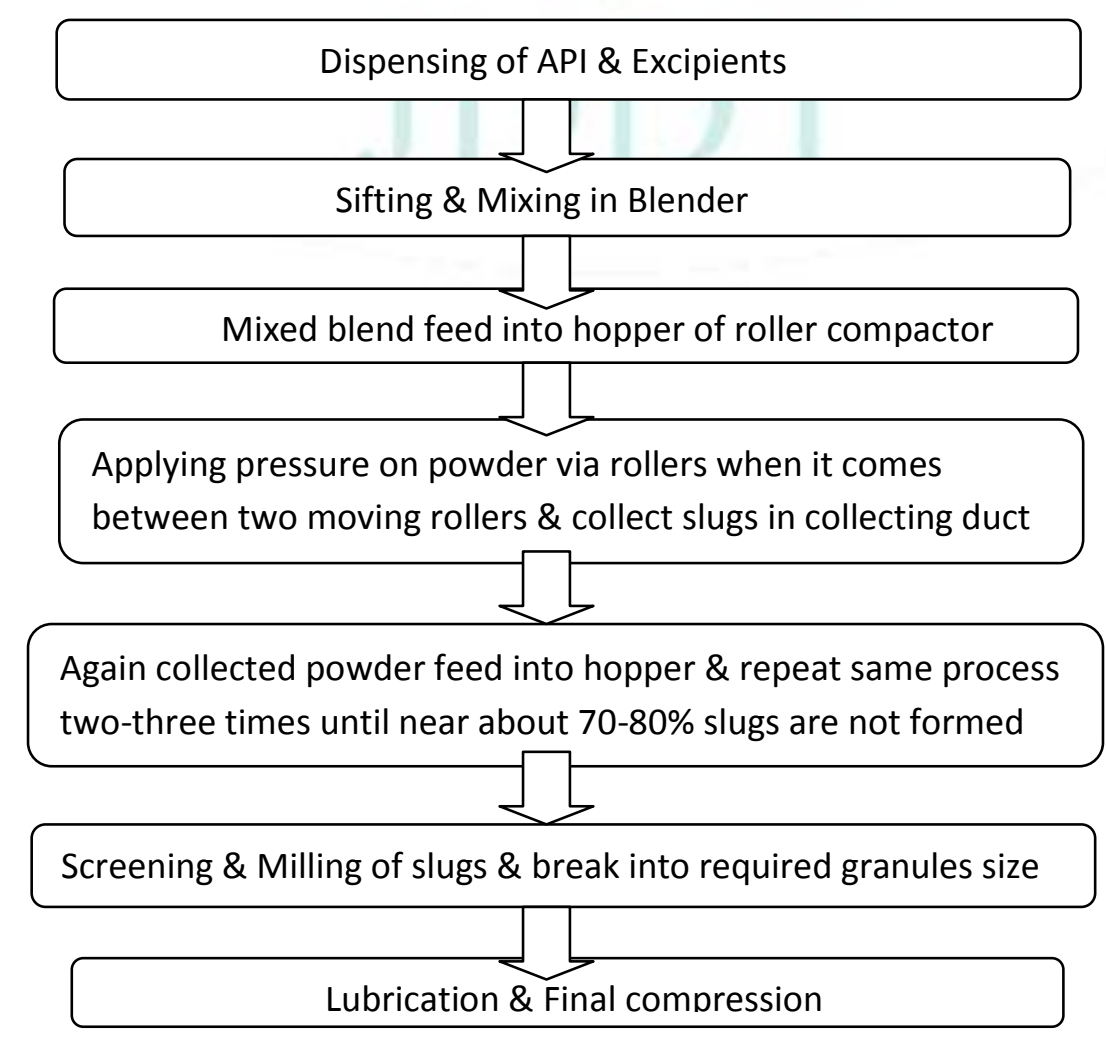




\section{* Tablet molding}

In this technology, water-soluble ingredients are used so that tablet disintegrate and dissolve rapidly. The powder blend is moistened with a hydro alcoholic solvent and is molded in to tablet using compression pressure lower than used in conventional tablets compression. The solvent is then removed by air-drying. Molded tablets have a porous structure that enhances dissolution. Two problems commonly encountered are mechanical strength and poor taste masking characteristics. Using binding agents such as sucrose, acacia or poly vinyl pyrrolidone can increase the mechanical strength of the tablet. To overcome poor taste masking characteristic Van Scoik incorporated drug containing discrete particles, which were formed by spray congealing a molten mixture of hydrogenated cottonseed oil, sodium bicarbonate, lecithin, polyethylene glycol and active ingredient into a lactose based tablet triturate form. ${ }^{14}$

\section{* Wet granulation method}

Wet granulation is a process of using a liquid binder to lightly agglomerate the powder mixture. The amount of liquid has to be properly controlled, as over-wetting will cause the granules to be too hard and under-wetting will cause them to be too soft and friable. Aqueous solutions have the advantage of being safer to deal with than solvent-based systems but may not be suitable for drugs which are degraded by hydrolysis.

\section{Procedure}

- The active ingredient and excipients are weighed and mixed.

- The wet granulate is prepared by adding the liquid binder-adhesive to the powder blend and mixing thoroughly. Examples of binders/adhesives include aqueous preparations of corn starch, natural gums such as acacia, and cellulose derivatives such as methyl cellulose, gelatin and povidone.

- Screening the damp mass through a mesh to form pellets or granules.

- Drying the granulation. A conventional tray-dryer or fluid-bed dryer are most commonly used.

- After the granules are dried, they are passed through a screen of smaller size than the one used for the wet mass to create granules of uniform size.

- Low shear wet granulation processes use very simple mixing equipment, and can take a considerable time to achieve a uniformly mixed state. High shear wet granulation processes use equipment that mixes the powder and liquid at a very fast rate, and thus speeds up the manufacturing process. Fluid bed granulation is a multiple-step wet granulation process performed in the same vessel to pre-heat, granulate, and dry the powders. It is used because it allows close control of the granulation process. ${ }^{10}$

\section{* Mass-Extrusion}

This technology involves softening the active blend using the solvent mixture of water-soluble polyethylene glycol and methanol and subsequent expulsion of softened mass through the extruder or syringe to get a cylinder of the product into even segments using heated blade to form tablets. The dried cylinder can also be used to coat granules for bitter drugs and thereby achieve taste masking. ${ }^{16}$

\section{PROBLEMS IN TABLET MANUFACTURING}

An ideal tablet should be free from any visual defect or functional defect. The advancements and innovations in tablet manufacture have not decreased the problems, often encountered in the production, instead have increased the problems, mainly because of the complexities of tablet presses; and/or the greater demands of quality. An industrial pharmacist usually encounters number of problems during manufacturing. Majority of visual defects are due to inadequate fines or inadequate moisture in the granules ready for compression or due to faulty machine setting. Functional defects are due to faulty formulation. Solving many of the manufacturing problems requires an indepth knowledge of granulation processing and tablet presses and is acquired only through an exhaustive study and a rich experience.

Following are the defects that are found during tablet manufacturing: $5,15,17$

1. Weight variation

2. Capping

3. Lamination / Laminating

4. Cracking

5. Chipping

6. Sticking / Picking

7. Mottling

8. Double impression

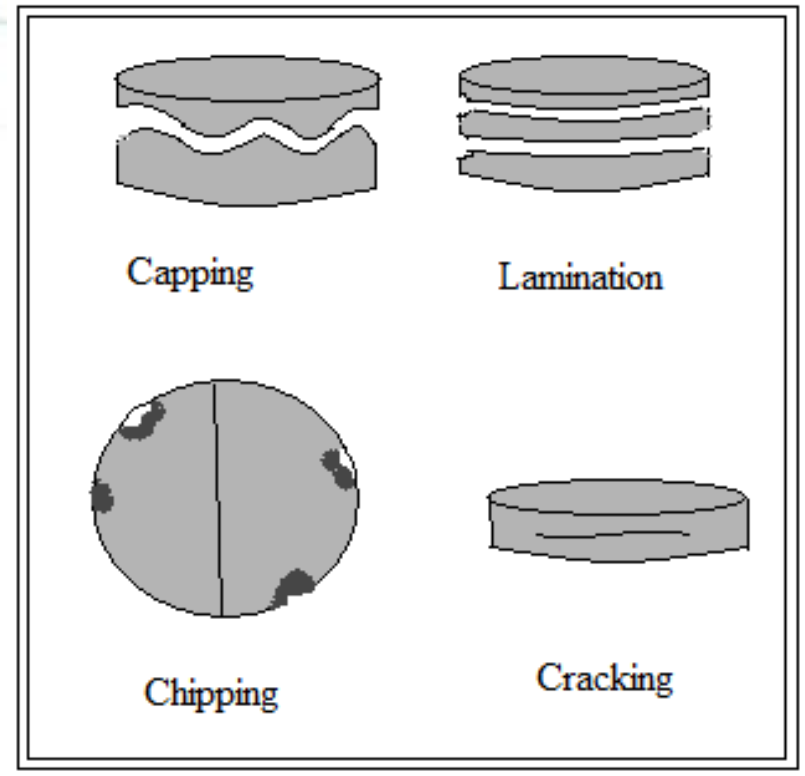

Figure 3: problems in tablet manufacturing 


\section{EVALUATION OF IMMEDIATE RELEASE TABLETS}

The blend is evaluated by following tests. ${ }^{17,18,19}$

1. Angle of repose

2. Bulk density

3. Tapped density

4. Carr's index

5. Hausner's Ratio

\section{Angle of repose}

Angle of repose was determined by using funnel method. The accurately weighed blend was taken in a funnel. The height of the funnel was adjusted in such a way that the tip of the funnel just touches the apex of the heap of blend. The drug excipient blend was allowed to flow through the funnel freely on to the surface. The diameter of the powder cone was measured and angle of repose was calculated using the following equation. ${ }^{12}$

Tan $=\mathbf{h} / \mathbf{r}$

Where $h$ and $r$ are the height and radius of the powder conc.

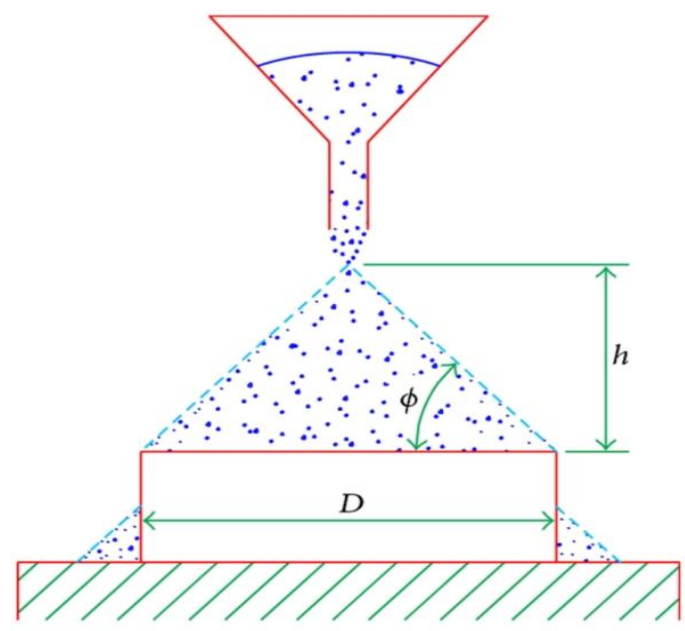

Figure 4: Measurement of angle of repose (Fixed Funnel method).

\section{Bulk density}

Bulk density was determined by pouring a weighed quantity of tablet blend into graduated cylinder and measuring the height. Bulk density is the ratio of mass of tablet blend to bulk volume. It was calculated in $\mathrm{gm} / \mathrm{cm} 3$ by the formula.

Bulk Density $(\mathrm{BD})=$ Weight of granules $(\mathrm{m}) /$ untapped volume of granules $(\mathrm{v})$.

Here; $\mathrm{m}=$ weight of powder or granules $(\mathrm{gm})$

$\mathrm{v}=$ Bulk Volume (cm.3)

\section{Tapped Density}

Tapped density is ratio of mass of tablet blend to tapped volume of tablet blend. Accurately weighed amount of tablet blend poured in graduated cylinder and height is measured. Then cylinder was allowed to 100tap under its own weight onto a hard surface. The tapping was continued until no further change in height was noted it was calculated in $\mathrm{gm} / \mathrm{cm} 3$ by the formula.

Tapped Density (TD) = Weight of granules (m) /tapped volume of granules (v).

Here; $\mathrm{m}=$ weight of powder or granules $(\mathrm{gm})$

$\mathrm{v}=$ Tapped Volume $(\mathrm{cm} .3)$

\section{Compressibility Index}

The Compressibility Index of the blends was determined by Carr's compressibility index.

4. Carr's compressibility index $(\%)=$ Compressibility is the ability of powder to decrease in volume under pressure using bulk density and tapped density the percentage compressibility of powder were determined, which is given as carr's compressibility index.

It is indirectly related to the relative flow rate. Carr's compressibility index was determined by the given formula.

\section{Carr's Index $(\%)=[($ TBD-LBD $)$ X 100 $] /$ TBD}

5. Hauser's ratio $=$ Hausner's ratio indicates the flow properties of powder and measured by the ratio of tapped density to bulk density. Hausner's ratio was determined by the given Formula.

\section{Hausner's Ratio = Tapped density/ Poured density}

Hausner's ratio $<1.25-$ Good flow $=20 \%$ Carr $1.25-$ Poor flow $=33 \%$ Carr

\section{Compression}

Mixed Blends is compressed by direct compression method using Cadmach single punch machine. Caput punches and die $(8 \mathrm{~mm}$.) were used in this study.

\section{In-vitro Evaluation of the prepared tablets}

These tests are as following

1. Appearance

2. Thickness

3. Hardness

4. Weight variation

5. Friability

6. Disintegration

7. Drug content

8. In vitro Dissolution

9. Stability studies

\section{Appearance}

The general appearance of tablet is its visual identity and all over elegance, shape, color, surface textures. These all parameters are essential for consumer acceptance.

\section{Thickness}

The thickness of the tablets was determined by using vernier calipers. Randomly 10 tablets selected were used for determination of thickness that expressed in 
Mean \pm SD and unit is $\mathrm{mm}$.

\section{Hardness}

The hardness of tablet is an indication of its strength against resistance of tablets to capping, abrasion or breakage under conditions of storage, transportation and handling before usage. Measuring the force required to break the tablet across tests it. Hardness of 10 tablets (randomly) from whole tablet batch was determined by Monsanto hardness tester. Hardness measured in $\mathrm{kg} / \mathrm{cm}^{2}$.

\section{Weight variation}

The weight variation test is carried out in order to ensure uniformity in the weight of tablets in a batch. The total weight of 20 tablets randomly from whole batch was determined and the average was calculated. The individual weights of the tablets were also determined accurately and the weight variation was calculated.

\section{Friability test}

Friability is the loss of weight of tablet in the container due to removal of fine particles from the surface during transportation or handling. Roche friabilator was employed for finding the friability of the tablets. For tablets with an average weight of $0.65 \mathrm{~g}$ or less take a sample of whole tablets corresponding to about $6.5 \mathrm{~g}$ and for tablets with an average weight of more than 0.65 $\mathrm{g}$ take a sample of 10 whole tablets. Roche friabilator is rotated at $25 \mathrm{rpm}$ for 4 minutes for 100rounds. The tablets were dedusted and weighed again. The percentage of weight loss was calculated using the formula

$$
\begin{aligned}
& \% \mathrm{f}=\mathrm{W} 0-\mathrm{W} 1 / \mathrm{W} 0 * 100 \\
& \% \mathrm{f}=\text { Percentage friability } \\
& \mathrm{W} 0=\text { Initial weight }(\text { Before test }) \\
& \mathrm{W} 1=\text { Final weight (After test) }
\end{aligned}
$$

\section{Disintegration test}

The USP device to rest disintegration was six glass tubes that are " 3 long, open at the top, and held against 10 " screen at the bottom end of the basket rack assembly. One tablet is placed in each tube and the basket rack is poisoned in 1 liter beaker of distilled water at $37 \pm 2$ o $\mathrm{C}$, such that the tablets remain below the surface of the liquid on their upward movement and descend not closer than $2.5 \mathrm{~cm}$ from the bottom of the beaker.

\section{Drug content}

10 tablets were powdered and 100mg drug equivalent powder dissolved in suitable media buffer or $0.1 \mathrm{~N} \mathrm{HCl}$. Volume of the solution made up to $100 \mathrm{ml}$ by that media. Solution was filtered and diluted 100times and analyzed spectrophotometrically and further Calculation carried out to determine drug content in one tablet.

\section{In vitro drug release studies}

The immediate release tablets are subjected to in vitro drug release studies in $\mathrm{pH} 6.8$ phosphate buffer or $0.1 \mathrm{~N}$ $\mathrm{HCl}$ for 30 minutes to access the ability of the formulation for providing immediate drug delivery. Drug release studies were carried out in dissolution test apparatus using specified volume $900 \mathrm{ml}$ of dissolution media maintained at $37 \pm 100 \mathrm{C}$. The tablets are kept in the cylindrical basket or directly placed in medium with paddle then rotated at $100 \mathrm{rpm}$. $5 \mathrm{ml}$ of the sample from the dissolution medium are withdrawn at each time interval $(5,10,15 \& 30$ minutes) and $5 \mathrm{ml}$ of fresh medium was replaced each time. The samples were filtered and from the filtrate $1 \mathrm{ml}$ was taken and diluted to $10 \mathrm{ml}$. These samples were analyzed spectrophotometrically and further calculation was carried out to get drug release. The drug released data were plotted and tested with zero order (Cumulative \% drug released Vs time), First order (Log \% Remained Vs time). The in vitro dissolution kinetic parameters, dissolution rate constants, correlation coefficient and dissolution efficiency were calculated.

\section{Dissolution Profile}

The compositions of the present invention preferably are immediate release compositions from which about $50 \%$ of the micronized drug is dissolved in vitro within about 15 minutes, more preferably at least about $80 \%$ of the drug is dissolved in vitro within about 30 minutes, and still more preferably at least about $90 \%$ of the e is dissolved in vitro within about 45 minutes using $1 \%$ sodium dodecyl sulfate (SDS) in water as the dissolution medium at $37^{\circ} \mathrm{C}$.

\section{Stability study}

Stability is defined as the ability of a particular drug or dosage form in a specific container to remain within its physical, chemical, therapeutic, and toxicological specifications. Drug decomposition or degradation occurs during storage, because of chemical alteration of the active ingredients or due to product instability, lowering the concentration of the drug in the dosage form. Stability study of the dosage form must include a section for product characterization and another section to study the product stability during storage. Formulations are evaluated for their appearance, possible weight gain in drug content thickness, flatness, folding endurance, tensile strength, moisture content and moisture uptake, and in-vitro release study by keeping dosage form in different temperature and humidity condition after a specified time. The stability study indicates that the formulation is quite stable at different conditions of storage.

\section{Recommended long-term and accelerated storage conditions}

Study Storage condition Minimum time period covered by data at submission

Long term $-25^{\circ} \mathrm{C} \pm 2{ }^{\circ} \mathrm{C} / 60 \% \mathrm{RH} \pm 5 \% \mathrm{RH}$ or $30^{\circ} \mathrm{C} \pm$ $2{ }^{\circ} \mathrm{C} / 65 \% \mathrm{RH} \pm 5 \% \mathrm{RH} 12$ months

Intermediate $-30^{\circ} \mathrm{C} \pm 2{ }^{\circ} \mathrm{C} / 65 \% \mathrm{RH} \pm 5 \% \mathrm{RH} 6$ months

Accelerated $-40^{\circ} \mathrm{C} \pm 2^{\circ} \mathrm{C} / 75 \% \mathrm{RH} \pm 5 \%$ RH 6 months.

\section{CONCLUSION}

A new dosage format, the immediate release pharmaceutical form has been developed which offers 
the combined advantages of ease of dosing and convenience of dosing. These tablets are designed to release the medicaments with an enhanced rate. To fulfill these medical needs, formulation have devoted considerable efforts to developing a novel types of tablet dosages for oral a administration, one that disintegrant and dissolve rapidly with enhanced dissolution. An extension of market exclusivity, which can be provide by immediate release dosage form leads to increase revenue, while also targeting underserved and under treated patent population. Due to the constraints of the current technologies there is a need for improved manufacturing processes for immediate release pharmaceutical form that are mechanically strong, allowing ease of handling and packaging and with production costs similar to that of conventional tablets.

\section{REFERENCES}

1. Leon Lachman, Herbert A, Liberman and Joseph L. Kaing: The Theory And Practice Of Industrial Pharmacy: 293-303.

2. Bhavin Patel, Dr. M.S. Ranawat, Dr. Chetan Singh Chauhan, Jaimin Modi Design, Development and Characterization of Immediate Release Tablet of Pioglitazone. JPSBR, March April 2013; 3(2): 91-99.

3. Aulton'S Pharmaceutics, The Design \& Manufacture Of Medicines,Biopharmaceutics And Pharmacokinetics, A Treatise, Second Edition, Valabh Prakashan, 315-384. Syed A, et al, "Immediate Release Drug Delivery Systems: A Review", International journals of Biopharmaceutical \& Toxicological Research., 2001.

4. Ansel'S Pharmaceutical Dosage Forms \& Drug Delivery Systems, Eighth Edition, 227-260.

5. Rana AS, Hari Kumar SL, Manufacturing Defects of Tablets - A Review, Journal of Drug Delivery and Therapeutics, 2013; 3(6):200-206. doi:10.22270/jddt.v3i6.722

6. Vaishali Kilor, Nidhi Sapkal, Awari J, Shewale B. Development And Characterization Of Enteric-Coated Immediate-Release Pellets Of Aceclofenac By Extrusion/Spheronization Technique Using Carrageenan As A Pelletizing Agent, AAPS Pharmscitech, 2010; 11(1): 336343.

7. Manish Jaimini* and Saurabh Rawat- A Review on Immediate Release Drug Delivery System, RJPBCS, AprilJune 2013; 4(2): 1726.

8. Rawlins EA. Tablets and Capsules. In: Bentleys.Text book of pharmaceutics. New Delhi: All India Traveller Publishers., 2006; 234-310

9. Cooper, J., Gunn, C., "Powder flow and compaction", In: Carter SJ, eds. Tutorial Pharmacy. CBS Publishers and Distributors, New Delhi, India. 1986; 211-233.

10. . Dedhiya et al, "Lercanidipine immediate release compositions" United States Patent Application 2006.

11. Dandare MS et al. Bilayer tablet: A Novel approach for immediate release of telmisartan and hydrochlorthaizide

combination. International Journal of Pharmacy \& Technology April 2012; 4(1): 3970-3983.

12. Margret Chandira. R., Jayakar.B, Pasupathi, A. Chakrabarty and BL Maruya P: Design, Development and Evaluation of Immediate Release Atorvastatin and Sustained Release Gliclazide Tablets, Journal of Pharmacy Research. 2009; 6(2).

13. Bhowmick et al, Fast Dissolving Tablet: An Overview, Journal of Chemical and Pharmaceutical Research, 2009, 1(1): $163-177$

14. A Gupta, AK Mishra, V Gupta, P Bansal, R Singh and AK Singh: Review Article, Recent Trends Of Fast Dissolving Tablet - An Overview Of Formulation Technology, International Journal Of Pharmaceutical \& Biological Archives., 2010; 1(1): 1 - 10.

15. Reddy LH: Fast Dissolving Drug Delivery Systems: A Review Of The Literature, IJPS. 2002: 331-336

16. R. Natarajan, Rohit Vaishnani, and NN. Rajendran,Formulation and Evaluation Immediate Release Tablets of Paroxetine $\mathrm{HCl}$ Using Different Superdisintegrants, International Journal of Research in Pharmaceutical and Biomedical Sciences, Vol. 2 (3) Jul Sep 2011.

17. Garg A, Gupta M, Taste masking and formulation development \& evaluation of mouth dissolving tablets of levocetrizine dihydrochloride. Journal of Drug Delivery and Therapeutics, 2013; 3(3):123-130. doi: $10.22270 / j d d t . v 3 i 3.514$

18. Sood $\mathrm{R}$ et al. Immediate release antihypertensive valsartan oral tablet: A Review. Journal of Scientific Research in Pharmacy May 2012; 1(2): 20-26.

19. Srinivas Pannala, Mahalaxmi Rathnanand,Preparation and in vitro evaluation of Nizatidine immediate release tablets, International Journal of PharmTech Research, Vol.3, No.3 pp 1688-1692, July-Sept 2011 